\title{
Synthesis of Carbon Nano Materials from Carbohydrate Rich Biogenic Precursors using Chemical Vapor Deposition Method and Optimization of Parameters by Taguchi Optimization Method
}

\author{
Rohit Kumar* \\ Senior Research Fellow, Department of Botany \& Biotechnology, T. M. Bhagalpur University, Bhagalpur, India \\ *Corresponding author: rohit.biotech05@gmail.com
}

\begin{abstract}
Carbon Nano Materials (CNM) from biogenic carbohydrate rich non-edible precursors such as Syzygium cumini (Jamun), Tamarindus indica (Imli) and Litchi chinensis (Imli) seeds were synthesized by chemical vapour deposition method (CVD). Parameters were optimized by Taguchi optimization method, four parameters such as precursor, temperature, carrier gas and duration and three levels $S$. cumini, $T$. indica and $L$. chinensis as a precursor, Argon (Ar), Nitrogen $\left(\mathbf{N}_{2}\right)$ and Hydrogen $\left(\mathrm{H}_{2}\right)$ as a carrier gas, 1 hour (hr), 2 hours and 3 hours (hrs) for duration of pyrolysis, $800^{\circ} \mathrm{C}, 900^{\circ} \mathrm{C}$ and $1000^{\circ} \mathrm{C}$ for temperature were selected. In the present work, impact of precursor is $35.84 \%$ which is the most effective factor than temperature $\mathbf{2 9 . 5 9 \% )}$ and other parameters such as duration $(\mathbf{1 9 . 5 0 \%})$ and the least effective factor is carrier gas $(\mathbf{1 5 . 0 7 \%})$. Impact of parameter on the yield which described by the deviation of signal to noise $(\mathrm{S} / \mathrm{N})$ ratio. The result of deviation of $\mathrm{S} / \mathrm{N}$ ratio shows $T$. indica seed (precursor), ${ }^{900}{ }^{\circ} \mathrm{C}$ (temperature), $2 \mathrm{hr}$ (duration) and $\mathrm{Ar}$ (carrier gas) are the best parameters. The morphology of CNM is studied by SEM characterization and the nature of synthesized CNM by RAMAN spectroscopy.
\end{abstract}

Keywords: Carbon nano material, Carbohydrate rich nonedible seeds, Pyrolysis, SEM, Taguchi optimization, RAMAN spectroscopy.

\section{Introduction}

Using petroleum derived materials as precursor, Carbon nano materials (CNMs) are usually synthesized. As petroleum derived materials are comparatively expensive and also they are at the verge of depletion in the near future. Hence, there is the need to look for other sources of precursors to synthesize CNMs. While following the principle of Green Chemistry, it is desirable that the raw material for any industrial process must be renewable rather than the depleting natural resources. It is one of the prime requirements to explore regenerative materials for synthesis of CNM, however, with high efficiency. Sharon and co-workers [1]-[4] firstly synthesized carbon nano tubes (CNT) from plant-derived precursors and since then there have been efforts in this direction in different parts of the world. Scientists have been exploring environment- friendly sources of CNMs. Efforts are being made to establish the conditions for growing multi walled carbon nanotube (MWCNTs), singlewalled carbon nano tubes (SWCNTs) and vertically aligned MWCNTs using suitable catalytic support by a simple and inexpensive chemical vapour deposition (CVD) techniques. There are different plant derivatives as well as plant parts which have successfully been used for the synthesis of carbon nano materials under pyrolytic conditions (5-9). They also synthesize CNM by a modified tradition sources from vegetable sources [10]-[12]. Almost all plant parts (roots, stem, leaves, seeds etc.) and plant derived products (pinene, latex, oil, juice, camphor) have been used as precursors of CNMs. The choice of precursor is primarily based on wide availability of the plant or plant parts. The next criterion is the percentage of hydrocarbon content (oil or fatty acid, cellulose, polysaccharide, lignin etc.) of the chosen plant precursors. Researchers have also used sugarcane juice, an algae Euglena, cotton, fibre, rice straw, corn cob, latex of Calotropis, bamboo, and pretreated rice straw as raw materials, however, with promising results. The use of palm oil has yielded aligned CNTs arrays. Spray pyrolysis of biodiesel has yielded well defined multi walled carbon nano tubes [13]. The Carbon Nano Material (CNM) is determined by the nature of precursor. There are several reports with regard to the carbon nano materials being derived from the seeds including Grapes seeds, T. indica, Soybean, Anacardium, Ritha and Castor [14]-[17].

The aims of the present work are to synthesize carbon nano materials from precursors derived from carbohydrate rich nonedible seeds of plants and parameters were optimized by Taguchi optimization method using CVD process. It has been decided to use various types of carbohydrate rich seeds as Jamun (Syzygium cumini (L.) Skeels), Imli (Tamarindus indica L.) and Litchi (Litchi chinensis Sonn.) to synthesize carbon 
nano materials. These seeds contain different amount of carbohydrate, oil and protein constituents, these are rich source of carbon.

\section{Materials and Methods}

For the synthesis of CNM, the seeds of $S$. cumini, $T$. indica and $L$. chinensis were purchased from local market, CVD furnace was used for pyrolysis.CVD method was used for Pyrolysis of these three type of seeds. The parameters considered were 1) three different gases i.e. Argon (Ar), Nitrogen $\left(\mathrm{N}_{2}\right)$, and Hydrogen $\left(\mathrm{H}_{2}\right)$ 2) three different temperatures i.e. $800^{\circ} \mathrm{C}, 900^{\circ} \mathrm{C}$ and $1000^{\circ} \mathrm{C}$ and 3) duration of pyrolysis $1 \mathrm{hr}, 2 \mathrm{hrs}$, and $3 \mathrm{hrs}$. The seeds were washed with $\mathrm{D} / \mathrm{W}$ and dried in the muffle furnace at $60^{\circ} \mathrm{C}$ for $6 \mathrm{hrs}$ and the crushed into powder form with the help of mortar and pestle. After crushing, took known amount of precursor into a quartz boat for pyrolysis.

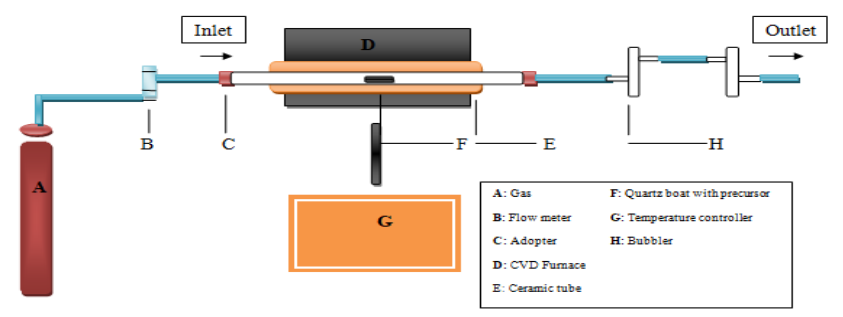

Fig. 1. Schematic diagram of CVD set up

CVD apparatus was used for the synthesis of carbon nano materials from carbohydrate rich non-edible seeds. Known amount of crushed seeds were taken in a quartz boat and placed in the centre of $1 \mathrm{~m}$ long quartz tube (inside furnace) that was inserted in the furnace. The carrier gas was flushed into the quartz tube at a higher flow rate $(150 \mathrm{ml} / \mathrm{min})$ so as to remove oxygen and the quartz tube was closed. Then the purging of gas was continued at the flow rate $(25 \mathrm{ml} / \mathrm{min})$ during pyrolysis. Desired temperatures were set when the temperature reaches $450^{\circ} \mathrm{C}-500^{\circ} \mathrm{C}$, the biomass starts vaporizing inside the tube and flows along with the carrier gas toward outlet of the tube. By the time the temperature reached $700^{\circ} \mathrm{C}$ the flow rate was gradually decreased and stopped. When it reached at set temperature, it was maintained at that temperature for desired set duration. At high temperature, the hydrocarbons are decomposed and converted into simpler form of carbon. The non-carbonaceous material gets removed along with the carrier gas from the furnace and remnant carbonized carbon material are left in the quartz boat.

\section{A. Standardization of synthesis parameters (Taguchi Optimization of Parameters)}

For the present CVD process four parameters, each with three variables were to be tried. Therefore, for the present work, experiment was designed by Taguchi Optimization method [18]. This method is a statistical method developed by Genichi Taghuchi (1950) of Nippon Telephones and Telegraph
Company, Japan for improving the manufactured goods, marketing \& advertising, more recently, even applicable for the research field. In this method statistically designed orthogonal arrays (OA) [19]-[20] are being of used to evaluate comparatively smaller number of experiments. It is a simple efficient and systematic approach for the optimization of experimental parameters [21]-[22]. Using Taguchi method one can get information about the most effective parameters controlling the formation of a required product by carrying out only 9 experiments. The Taguchi philosophy of variability reduction is based on the fact that there is a 'best' value for the product. The Taguchi strategy attempts to find the combination of the values of the controllable design variables that minimizes the expected loss over the uncontrollable noise space.

\section{B. Application of Taguchi Optimization for Present work}

Four parameters considered for the synthesis of CNM from plant seeds are Carrier Gases, Precursors, Temperatures, and Duration of Pyrolysis. In total, three levels of each parameter were selected (Table 1).

Table 1

Four parameters used for Taguchi Optimization Technique for Carbohydrate-rich non edible seed

\begin{tabular}{|l|l|l|l|l|}
\hline \multirow{2}{*}{ S.No. } & \multirow{2}{*}{ Parameters } & \multicolumn{3}{|c|}{ Levels of Parameters } \\
\cline { 3 - 5 } & & Level 1 & \multicolumn{1}{c|}{ Level 2 } & \multicolumn{1}{c|}{ Level 3 } \\
\hline 1 & Gas & $\mathrm{Ar}$ & $\mathrm{N}_{2}$ & $\mathrm{H}_{2}$ \\
\hline 2 & Temperature $\left({ }^{0} \mathrm{C}\right)$ & 800 & 900 & 1000 \\
\hline 3 & Duration $(\mathrm{hr})$ & 1 & 2 & 3 \\
\hline 4 & Precursor $($ Seeds) & $\begin{array}{l}\text { Syzygium } \\
\text { cumini }\end{array}$ & $\begin{array}{l}\text { Tamarindus } \\
\text { indica }\end{array}$ & $\begin{array}{l}\text { Litchi } \\
\text { chinensis }\end{array}$ \\
\hline
\end{tabular}

Using above mentioned parameters and its level, L9 orthogonal matrix was designed (Table 2).

Taguchi optimization method is a statistical method [23] in which simple mean of analysis and optimization of complex systems based on the statistical analysis of data are optimized. A special design of orthogonal arrays (OA) is used in Taguchi optimization method to study the entire parameter space with only a small number of experiments. This approach of the statistical analysis is comparatively simple for optimization of experimental designs in order to evaluate performance and quality of the experiments.

Table 2

Arrangement of L9 orthogonal parameters as per Taguchi Optimization Technique for Carbohydrate rich non-edible seeds

\begin{tabular}{|l|l|l|l|l|}
\hline $\begin{array}{c}\text { Taguchi } \\
\text { Level }\end{array}$ & Gas & $\begin{array}{c}\text { Temperature } \\
\left({ }^{\mathbf{0}} \mathbf{C}\right)\end{array}$ & $\begin{array}{c}\text { Duration } \\
(\mathbf{h r})\end{array}$ & $\begin{array}{c}\text { Precursor } \\
(\text { Seed })\end{array}$ \\
\hline L1 & $\mathrm{Ar}$ & 800 & 1 & Syzygium cumini \\
\hline L2 & $\mathrm{Ar}$ & 900 & 2 & Tamarindus indica \\
\hline L3 & $\mathrm{Ar}$ & 1000 & 3 & Litchi chinensis \\
\hline L4 & $\mathrm{N}_{2}$ & 800 & 2 & Litchi chinensis \\
\hline L5 & $\mathrm{N}_{2}$ & 900 & 3 & Syzygium cumini \\
\hline L6 & $\mathrm{N}_{2}$ & 1000 & 1 & Tamarindus indica \\
\hline L7 & $\mathrm{H}_{2}$ & 800 & 3 & Tamarindus indica \\
\hline L8 & $\mathrm{H}_{2}$ & 900 & 1 & Litchi chinensis \\
\hline L9 & $\mathrm{H}_{2}$ & 1000 & 2 & Syzygium cumini \\
\hline
\end{tabular}


Statistical analysis of signal to noise $(\mathrm{S} / \mathrm{N})$ ratio and an analysis of variance (ANOVA) [24] has to be employed for determining relative importance of various factors. Orthogonal array (OA) analysis is completed by ANOVA and $\mathrm{S} / \mathrm{N}$ ratio. ANOVA is used to analyze the results of the OA (Orthogonal Arrays) experiment and to determine how much variation each quality (influencing factor) has contributed.

$\mathrm{S} / \mathrm{N}$ ratio is $\log$ function of desired output for optimization, which thereby, helps in data analysis and as well as in prediction of optimal results. An S/N ratio is a key part of the Taguchi optimization method and is often evaluated using a parameter design. Taguchi's S/N ratios are the performance statistics that recommends for selecting the best combination of the design variables. Larger the $\mathrm{S} / \mathrm{N}$ ratio more robust the design. For the best design, the parameter which gives $\mathrm{S} / \mathrm{N}$ ratio highest value is considered as the favoured parameter. Thus, to minimize the expected loss, one always finds the combination of the design variables, which maximizes the $\mathrm{SN}$ ratio performance statistic.

The $\mathrm{S} / \mathrm{N}$ is the ratio of the average response of the root mean square variation about the average response. Larger the $\mathrm{S} / \mathrm{N}$ ratio, smaller the measurement of error because the $\mathrm{S} / \mathrm{N}$ is the reciprocal of the variance of the measurement error. $\mathrm{S} / \mathrm{N}$ ratio is used to analyze the test run results because the $\mathrm{S} / \mathrm{N}$ ratio signifies the mean mean and variation (scatter) of the experimental results.

Calculations for 'Larger the Better': There are three categories of $\mathrm{S} / \mathrm{N}$ ratios (i) smaller the better, (ii) larger the better and (iii) nominal the best. In the present work target was to get larger quantity of carbon, therefore, "larger the better" is used for calculation using following equation:

$$
\mathrm{S} / \mathrm{N}=-10 \log _{10}\left[(1 / \mathrm{n}) \Sigma 1 / \mathrm{y}_{\mathrm{i}}{ }^{2}\right]
$$

Where " $y_{i}$ " is the mean response calculated as $\mathrm{y}=1 / \mathrm{n} \Sigma \mathrm{y}_{\mathrm{i}}$ and $\mathrm{n}$ is the number of experiments carried out under similar conditions.

Calculations for Effect of each parameter: To determine the effect of each parameter level $\left(\mathrm{m}_{\mathrm{i}}\right)$ average value of $\mathrm{S} / \mathrm{N}$ ratios was calculated for each parameter, using analysis of mean (ANOM). For this calculation, the $\mathrm{S} / \mathrm{N}$ ratios of each experiment with corresponding parameter levels are calculated using following equation:

$$
\mathrm{m}_{\mathrm{i}}=\left(1 / \mathrm{n}_{\mathrm{i}}\right) \Sigma \mathrm{S} / \mathrm{N}
$$

Where, $n_{i}$ is the number of experiments repeated with the same parameter levels.

There are two types of average value of $\mathrm{S} / \mathrm{N}$ ratio is calculated. One is the overall mean $\mathrm{S} / \mathrm{N}$ ratio calculated from the entire experiments for example from L9 experiment of L9 orthogonal array (i.e. from $\mathrm{S} / \mathrm{N}$ values given in table). Secondly, average $\mathrm{S} / \mathrm{N}$ ratio is calculated for each parameter from equation-1. The advantage of the average value of $\mathrm{S} / \mathrm{N}$ ratio, are considered to be the least effective parameters as compared to those parameters whose $\mathrm{S} / \mathrm{N}$ ratios are larger than mean $\mathrm{S} / \mathrm{N}$ ratio.

The parameters effects, i.e. the contribution of each experimental parameter to the quality characteristic are calculated by the analysis of variance (ANOVA). ANOVA is done by summing of squares (SOS) of variance of all levels of a given parameters. The relations that are used to determine the sum of the squares and the factor effect are given by the following equation:

$$
(\mathrm{SOS})=\Sigma \mathrm{N}_{\mathrm{i}}\left(\mathrm{m}_{\mathrm{i}}-<\mathrm{m}_{\mathrm{i}}>\right)^{2}
$$

Where $m_{i}$ gives the average of the levels contributions for each parameters levels to $\mathrm{S} / \mathrm{N}$ ratio, $\left\langle\mathrm{m}_{\mathrm{i}}\right\rangle$ is the average of mi for a given parameter and the coefficient and $\mathrm{Ni}$ represents the no. of repeats the experiment is conducted with the same factor level.

SOS is normalized with respect to the degree of freedom (DOF) of the corresponding process parameters.

$$
\mathrm{DOF}=\text { number of parameter level }-1
$$

If there are three levels for each parameters then DOF $=3-1$ $=2$

Some of square (SOS) of variances for all levels for a given parameter are divided by degree of freedom (DOF) of corresponding process parameter to obtain factor of effects (FOE) of various experimental parameters. The equation of calculation of FOE is following:

$$
\mathrm{FOE}=\mathrm{SOS} /[\mathrm{DOF} \times(\mathrm{SOS} / \mathrm{DOF})]
$$

Finally, percentage parameter effect is calculated as following:

$$
\text { Parameter effect } \%=100 \times \text { FOE }
$$

Using L9 orthogonal array nine sets of experiments were carried out. Results were calculated based on equations 1 to 3 mentioned above, nano and micro carbon materials were synthesized by CVD method from different non-edible seeds.

\section{Purification of CNM derived from Seeds}

Acid-refluxing the sample is an effective measure in reducing the amount of metal particles, amorphous carbon, and raw material based impurities and also for residual functional groups. Various acids such as $\mathrm{HCl}, \mathrm{HNO}_{3}, \mathrm{H}_{2} \mathrm{SO}_{4}$ are commonly used for purification of CNMs. For SEM treatment of our experimental seeds samples, the synthesized CNM was purified utilizing acid reflux with $\mathrm{HCl}$ and $\mathrm{HNO}_{3}$. In the present work, $1.01 \mathrm{gm}$ of crushed CNM produced was weighed and taken in chemical synthetic reactor/ three necked round bottomed flask. In the reaction vessel $100 \mathrm{~mL}$ Conc. $\mathrm{HCl}$ (36.5\%) and $100 \mathrm{~mL}$ Conc. $\mathrm{HNO}_{3}(63 \%)$ were added along with the sample and those were refluxed at $110^{\circ} \mathrm{C}$ for $12 \mathrm{hrs}$. Then 
after, the flask was allowed to cool for 6-8 hrs. The resulting black residual of the reflux process was centrifuged and subsequently the dark liquid was discarded. The powder thus obtained was washed with luke warm double distilled water for several times till the traces of acid was completely removed. The obtained powder was then dried in vacuum oven $(24$ hours). The sample was now ready for SEM analysis. Obtained CNM was analysed by SEM, and Raman Spectroscopy.

\section{Results and Discussions}

A. Carbon Nano Materials from carbohydrate rich non-edible seeds

Taguchi optimization method is a statistical method by which experimental parameters are optimized in a small number of experiments. On that basis the orthogonal table was constructed considering different combinations (four possible parameters) with a minimum of three variables of each parameter. We had selected the variable parameters such as carrier gas, temperature, duration and precursors (different type of carbohydrate rich non- edible seeds) and they all are orthogonal to each other. By using Taguchi Optimization technique, an orthogonal table was constructed in which three levels of parameters were used. Therefore, L9 orthogonal table was constructed by using the parameters and their levels as mentioned (Table 2). Pyrolysis was carried out for each set of conditions. Percentage (\%) of yield and $\mathrm{S} / \mathrm{N}$ ratio was calculated for each experimental result by using equation 1 . The yields of CNM as well as $\mathrm{S} / \mathrm{N}$ ratio calculated from each set are also given in table 3. Deviation of $\mathrm{S} / \mathrm{N}$ ratio was also calculated and factor of effect (FoE) was evaluated.

\section{B. Taguchi optimization on the yield of carbon}

So far as yield of carbon from pyrolysis of different seeds are concerned, Syzygium cumini and Litchi chinensis yielded 22 24\% carbon, whereas Tamarindus indica produced upto 23\% carbon. Earlier, Chaudhary et al. (2014) derived Carbon nano particles (21\% wt./wt.) from Litchi seeds, however, as compared to the amount of precursor used. Mopung et al. (2015) observed comparatively higher $28.89 \%$ of carbon yield the seed of Tamarindus indica at a temperature range of $500^{\circ} \mathrm{C}$ $-700^{\circ} \mathrm{C}$. Various parameters of pyrolysis do not seem to have much impact on the yield. However, it was observed that out of three seeds taken Syzygium cumini and Tamarindus indica yielded higher levels of carbon at lower temperature compared to Litchi chinensis. The decrease in CNM yield with increasing temperature could either be due to greater primary decomposition of biomass at higher temperature or through secondary decomposition of carbonaceous materials residues (Ming et. al., 2016). Signal to noise (S/N) ratio of CNM produced under different conditions is plotted in figure 2 . The purpose of the proposed work was to find out the best set of parameters for pyrolysis which could give the maximum amount of CNM. For calculation of the $\mathrm{S} / \mathrm{N}$ ratio "Larger the Better "condition was used. Among three types of carbohydrate rich non-edible seeds Tamarindus indica seeds appeared to give the best yield. Following Taguchi optimization, the deviation S/N ratio showed that $900^{\circ} \mathrm{C}$ temperature (as applied) and two hours' time of pyrolysis gave the higher yield of CNM. Amongst the three carrier gases applied, Argon was better suited than nitrogen and hydrogen for the yield of CNM. Since hydrogen is a reducing gas, it might have reduced the carbon during secondary decomposition of carbonaceous materials ( $\mathrm{Li}$ et al., 2017).

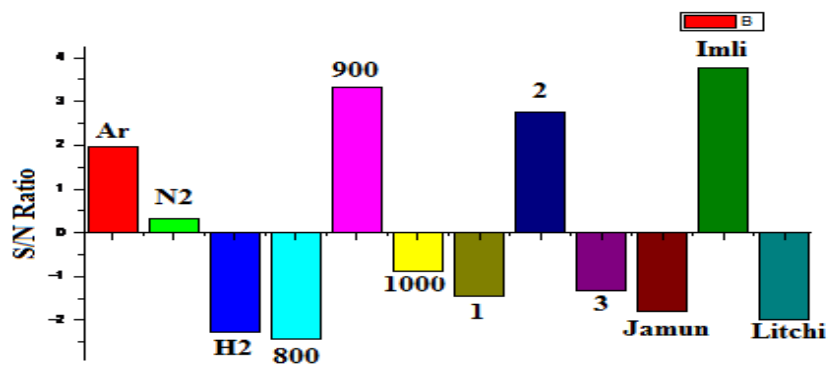

Fig. 2. Schematic representing showing impact of parameter on the CNM synthesis from Carbohydrate rich non-edible seeds (Syzygium cumini,

Tamarindus indica, Litchi chinensis), as per Taguchi calculations of $\mathrm{S} / \mathrm{N}$ ratio

The calculation of percentage impact of each parameter on the production of CNM (Table 4) suggests that precursor (35.84\%) has maximum impact on the experimental designing followed by temperature (29.59\%) then duration (19.50\%) and the least impact is that of carrier gas (15.07\%) which was shown in the pie diagram (figure 3). Sharon et al., 2011 [25] working at $800^{\circ} \mathrm{C}$ using Argon as carrier gas and pyrolyzing duration of 2 hours showed $15 \%$ impact compared to other parameters.

Table 3

Orthogonal array of parameters (Taguchi Optimization technique) set for pyrolysis of Syzygium cumini, Tamarindus indica and Litchi chinensis seeds. Yield and $\mathrm{S} / \mathrm{N}$ ratio of carbon CNM are also shown (Taguchi larger the better)

\begin{tabular}{|c|c|c|c|c|c|c|c|c|c|}
\hline $\begin{array}{c}\text { Taguchi } \\
\text { level }\end{array}$ & Gas & $\begin{array}{c}\text { Temperature } \\
\left({ }^{0} \mathrm{C}\right)\end{array}$ & $\begin{array}{c}\text { Duration } \\
\text { (hr) }\end{array}$ & Precursor (Seed) & $\begin{array}{c}\text { Precursor wt } \\
(\mathrm{gm})\end{array}$ & $\begin{array}{l}\text { Yield } \\
\text { (gm) }\end{array}$ & $\begin{array}{c}\text { Yield after } \\
\text { Purification (gm) }\end{array}$ & $\%$ yield & $\begin{array}{c}\text { S/N } \\
\text { Ratio }\end{array}$ \\
\hline L-1 & $\mathrm{Ar}$ & 800 & 1 & Syzygium cumini & 5 & 1.354 & 1.235 & 24.7 & 27.85 \\
\hline L-2 & $\mathrm{Ar}$ & 900 & 2 & Tamarindus indica & 5 & 0.870 & 0.680 & 13.6 & 22.67 \\
\hline L-3 & $\mathrm{Ar}$ & 1000 & 3 & Litchi chinensis & 5 & 1.212 & 1.166 & 23.32 & 27.35 \\
\hline L-4 & $\mathrm{N}_{2}$ & 800 & 2 & Litchi chinensis & 5 & 1.258 & 1.125 & 22.5 & 27.04 \\
\hline L-5 & $\mathrm{N}_{2}$ & 900 & 3 & Syzygium cumini & 5 & 1.108 & 1.050 & 21 & 26.44 \\
\hline L-6 & $\mathrm{N}_{2}$ & 1000 & 1 & Tamarindus indica & 5 & 1.100 & 1.000 & 20 & 26.02 \\
\hline L-7 & $\mathrm{H}_{2}$ & 800 & 3 & Tamarindus indica & 5 & 1.198 & 1.166 & 23.32 & 27.35 \\
\hline L-8 & $\mathrm{H}_{2}$ & 900 & 1 & Litchi chinensis & 5 & 1.256 & 1.172 & 23.44 & 27.40 \\
\hline L-9 & $\mathrm{H}_{2}$ & 1000 & 2 & Syzygium cumini & 5 & 1.335 & 1.164 & 23.28 & 27.34 \\
\hline & & & & & & & \multicolumn{2}{|l|}{ Mean S/N Ratio } & 26.60 \\
\hline
\end{tabular}




\section{IJRESM https://www.ijresm.com | ISSN (Online): 2581-5792 | RESAIM Publishing}

Detail of calculation was described in previous chapter.

Histogram of Percentage Factor Effect for different parameters (Fig. 4) showed that precursor had maximum level of impact followed by temperature and duration, however the impact of carrier gas had least impact.

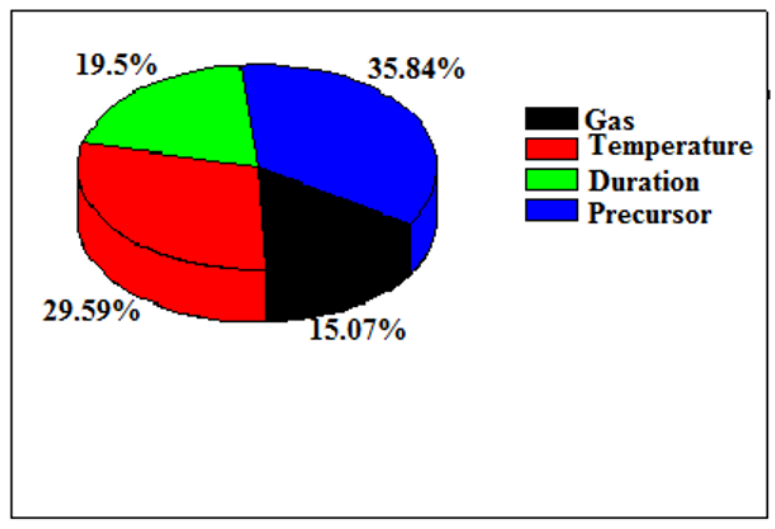

Fig. 3. Pie chart showing per cent factor of effects of each parameter

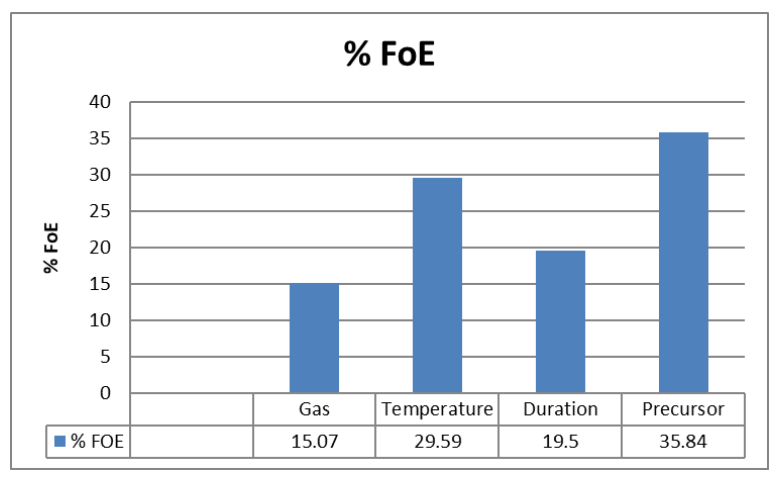

Fig. 4. Histogram of per cent Factor of Effect of different parameters

C. Scanning Electron Microscopy (SEM) micrographs of pyrolised Carbon materials from carbohydrate rich non-edible seeds

Morphological studies of SEM micrograph and observation

Table 4

Control parameters of the pyrolysis of non-edible seeds (Syzygium cumini, Tamarindus indica, Litchi chinensis) and their corresponding S/N ratio

\begin{tabular}{|c|c|c|c|c|c|c|c|c|c|c|c|c|}
\hline \multirow[t]{2}{*}{ Parameter } & \multicolumn{3}{|c|}{ Gas } & \multicolumn{3}{|c|}{ Temperature $\left({ }^{\circ} \mathrm{C}\right)$} & \multicolumn{3}{|c|}{ Time duration $(\mathrm{hr})$} & \multicolumn{3}{|c|}{ Precursor (seed) } \\
\hline & $\mathrm{Ar}$ & $\mathrm{N}_{2}$ & $\mathrm{H}_{2}$ & 800 & 900 & 1000 & 1 & 2 & 3 & S. cumini & T. indica & L. chinensis \\
\hline L1 & 27.85 & & & 27.85 & & & 27.85 & & & 27.85 & & \\
\hline L2 & 22.67 & & & & 22.67 & & & 22.67 & & & 22.67 & \\
\hline L3 & 27.35 & & & & & 27.35 & & & 27.35 & & & 27.35 \\
\hline L4 & & 27.04 & & 27.04 & & & & 27.04 & & & & 27.04 \\
\hline L5 & & 26.44 & & & 26.44 & & & & 26.44 & 26.44 & & \\
\hline L6 & & 26.02 & & & & 26.02 & 26.02 & & & & 26.02 & \\
\hline L7 & & & 27.35 & 27.35 & & & & & 27.35 & & 27.35 & \\
\hline L8 & & & 27.40 & & 27.40 & & 27.40 & & & & & 27.40 \\
\hline L9 & & & 27.34 & & & 27.34 & & 27.34 & & 27.34 & & \\
\hline $\begin{array}{l}\text { Sum } \\
(\mathrm{S} / \mathrm{N})\end{array}$ & 77.87 & 79.5 & 82.09 & 82.24 & 76.51 & 80.71 & 81.27 & 77.05 & 81.14 & 81.63 & 76.04 & $81.79 \mathrm{~s}$ \\
\hline Deviation S/N & 1.95 & 0.32 & -2.27 & -2.42 & 3.31 & -0.89 & -1.45 & 2.77 & -1.32 & -1.81 & 3.78 & -1.97 \\
\hline $\mathrm{m}_{\mathrm{i}}$ & 25.96 & 26.5 & 27.36 & 27.41 & 25.50 & 26.90 & 27.09 & 25.68 & 27.05 & 27.21 & 25.35 & 27.26 \\
\hline$\left\langle\mathrm{m}_{\mathrm{i}}\right\rangle$ & 26.60 & & & 26.60 & & & 26.60 & & & 26.60 & & \\
\hline $\mathrm{m}_{\mathrm{i}^{-}}-\left\langle\mathrm{m}_{\mathrm{i}}\right\rangle$ & -0.64 & -0.1 & 0.76 & 0.81 & -1.1 & 0.3 & 0.49 & -0.92 & 0.45 & 0.61 & -1.25 & 0.66 \\
\hline SOS & 2.99 & & & 5.87 & & & 3.87 & & & 7.11 & & \\
\hline SOS/DOF & 1.495 & & & 2.935 & & & 1.935 & & & 3.555 & & \\
\hline FoE $(\%)$ & 15.07 & & & 29.59 & & & 19.50 & & & 35.84 & & \\
\hline
\end{tabular}

of pyrolised different carbohydrate rich non-edible seeds (Syzygium cumini, Tamarindus indica and Litchi chinensis.) are represented in Table 5.

The SEM micrographs of CNMs (synthesized through CVD of the three precursors: Carbohydrate rich non-edible seeds: Syzygium cumini, Tamarindus indica and Litchi chinensis) are shown in this table.SEM micrographs are the experiments of different L levels (L1 - L9) as optimized by 'Taguchi method'. The SEM micrograph were obtained from the powder of precursors which revealed plate like structures.

The SEM micrographs of Syzygium cumini (L1, L5 and L9 (Table 5)) it was observed that the CNM morphology was multilayered smooth surface plates with porous side and the size range was approx. $30-750 \mathrm{~nm}$. In L1 the size of larger structures were about $150-750 \mathrm{~nm}$ and the size of smaller fragments was in the range of $30-100 \mathrm{~nm}$ in range. In L5, the size of larger structure was 100-2000 nm and the size of smaller fragments was approx. 50-100 $\mathrm{nm}$. In L9, the length of the larger structure was about $2200 \mathrm{~nm}$ and the size of smaller fragments was about 20-100 $\mathrm{nm}$ which was impregnated on the larger structures.

On observation and respective comparison of the SEM micrographs of CNM of Tamarindus indica (L2, L6 and L7 (Table 5)) it was found that the CNM morphology of L2 was multilayered plate with rough surface and porous sides, the size range was 40-2000 nm. The morphology of L6 showed that the structure with pits (bowl like) contained small fragments of CNM. The pit diameter was about $100 \mathrm{~nm}$, and larger fragments of $2200 \mathrm{~nm}$ in size while smaller fragments were of 30-60 nm size. The SEM micrograph of L7 showed that smooth surface plate with multilayered plates. The size of larger fragments was $1500 \mathrm{~nm}$ and smaller fragments of 30-100 nm. While working on T. indica seed parts, Munusamy et al. (2011) [15] found that the decoated $T$. indica seeds were non- porous, whereas the $T$. indica seeds char (TSC) and T-char were of porous structures. 
Table 5

SEM micrographs of carbohydrate rich seeds (Syzygium cumini, Tamarindus indica and Litchi chinensis) in relation to different parameters (carrier gas,

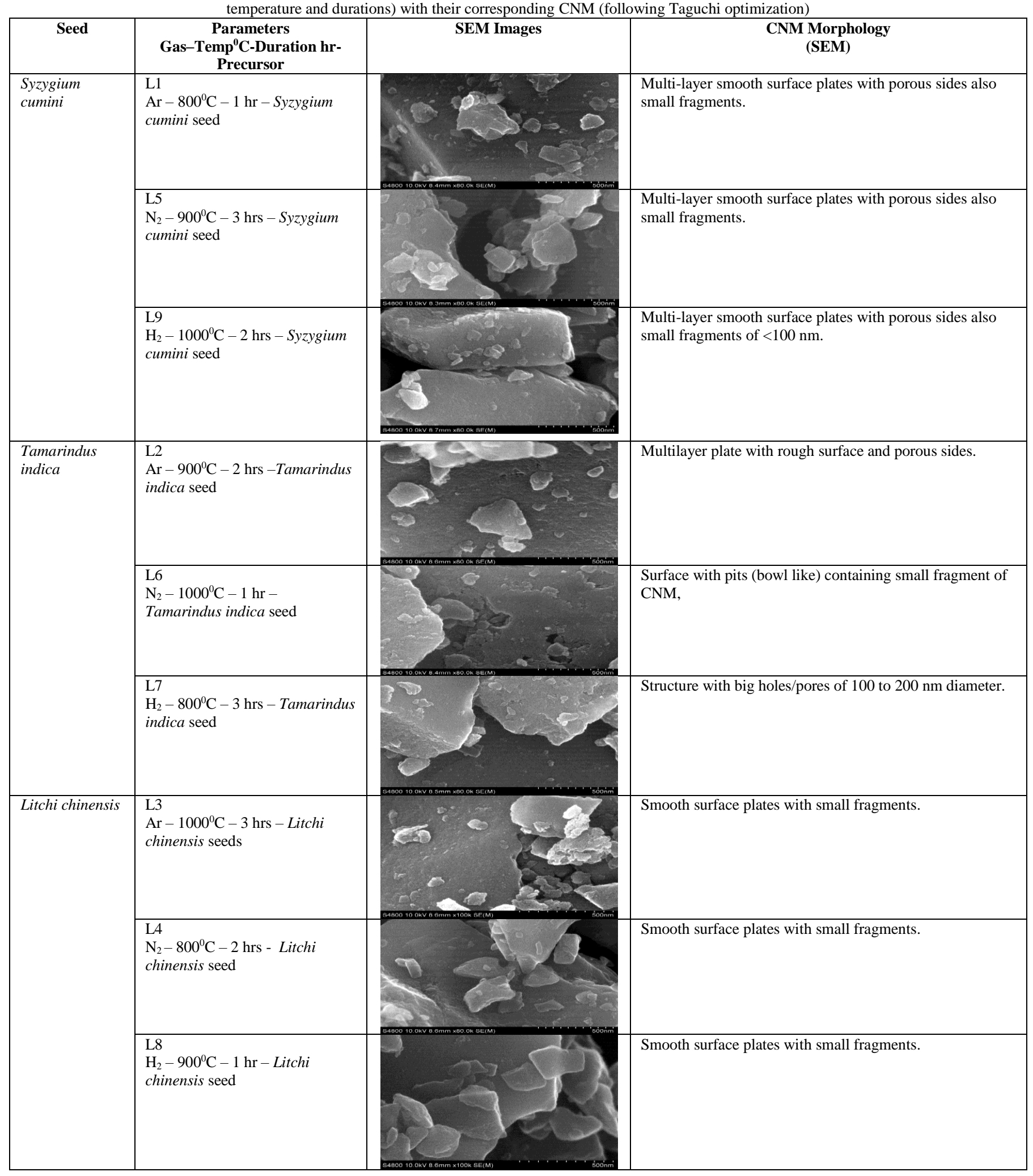


The observation of SEM micrograph of pyrolysed CNM of Litchi chinensis seeds (L3, L4 and L8 (Table 5)) had plate like morphology and the length of CNM was about $40-2500 \mathrm{~nm}$ in size. The morphology of all the three levels (L3, L4 and L8) of experiment were almost same but with variable of CNM. The larger structure of L3 was about $1500 \mathrm{~nm}$ and the smaller fragments of were of 40-200 $\mathrm{nm}$ in size. In L4, the larger structures was $2000 \mathrm{~nm}$ and the smaller fragments were of 50$250 \mathrm{~nm}$ in size. The size of L8 varied from $100-2500 \mathrm{~nm}$. Chaudhary and Bhowmick (2014) [26] observed 40-70nm range of CNPs in aggregated form in Litchi peel.

D. Result and Inference of Raman spectra of Carbohydrate rich seeds

Table 6

Raman inference of Syzygium cumini, Tamarindus indica and Litchi chinensis

\begin{tabular}{|l|l|l|l|l|l|}
\hline Sample name & $\begin{array}{c}\text { Pyrolysing } \\
\text { temp }\end{array}$ & $\begin{array}{c}\text { D- } \\
\text { band }\end{array}$ & $\begin{array}{c}\text { G- } \\
\text { band }\end{array}$ & $\begin{array}{c}\mathbf{I}_{\mathbf{D}} / \mathbf{I}_{\mathbf{G}} \\
\text { ratio }\end{array}$ & $\begin{array}{c}\text { 2D } \\
\text { peak }\end{array}$ \\
\hline $\begin{array}{l}\text { Jamun }(\mathrm{L} 1) \\
\text { Syzygium } \\
\text { cumini }\end{array}$ & $800^{\circ} \mathrm{C}$ & 1357 & 1604 & 0.874 & 2915 \\
\hline $\begin{array}{l}\text { Jamun } \text { (L5) } \\
\text { Syzygium } \\
\text { cumini }\end{array}$ & $900^{\circ} \mathrm{C}$ & 1366 & 1607 & 0.924 & 2915 \\
\hline $\begin{array}{l}\text { Jamun (L9) } \\
\text { Syzygium } \\
\text { cumini }\end{array}$ & $1000^{\circ} \mathrm{C}$ & 1367 & 1608 & 0.945 & 2919 \\
\hline $\begin{array}{l}\text { Tamarind } \text { (L7) } \\
\text { Tamarindus } \\
\text { indica }\end{array}$ & $800^{\circ} \mathrm{C}$ & 1367 & 1600 & 0.912 & 2919 \\
\hline $\begin{array}{l}\text { Tamarind } \text { (L2) } \\
\text { Tamarindus } \\
\text { indica }\end{array}$ & $900^{\circ} \mathrm{C}$ & 1365 & 1600 & 0.937 & 2910 \\
\hline $\begin{array}{l}\text { Tamarind } \text { (L6) } \\
\text { Tamarindus } \\
\text { indica }\end{array}$ & $1000^{\circ} \mathrm{C}$ & 1364 & 1601 & 0.939 & 2911 \\
\hline $\begin{array}{l}\text { Litchi } \text { (L4) } \\
\text { Litchi } \\
\text { chinensis }\end{array}$ & $800^{\circ} \mathrm{C}$ & 1367 & 1610 & 0.884 & 2900 \\
\hline $\begin{array}{l}\text { Litchi } \text { (L8) } \\
\text { Litchi } \\
\text { chinensis }\end{array}$ & $900^{\circ} \mathrm{C}$ & 1366 & 1602 & 0.945 & 2920 \\
\hline $\begin{array}{l}\text { Litchi } \text { (L3) } \\
\text { Litchi } \\
\text { chinensis }\end{array}$ & $1000^{\circ} \mathrm{C}$ & 1354 & 1619 & 0.998 & 2911 \\
\hline
\end{tabular}

E. Raman spectra of Jamun seeds (Syzgyium cumini)

In the Raman spectra of Taguchi optimized Syzygium cumini seeds, there was sharp peak of D- band L1 at 1357, L5 at 1366 \& L9 at 1367 and G- band of L1 at 1604, L5 at 1607 \& L9 at 1608 which revealed the presence of $\mathrm{sp}^{3}$ and $\mathrm{sp}^{2}$ carbon with defect (fig 5). In pure diamond this peak remains at 1332 and in pure graphite peak at 1580 . The ratio of it it's intensities show the defect in those materials. ID/IG ratio of L1 is 0.874 , L5 is 0.924 \& L9 is 0. 945. An additional blunt 2D peak revealed at 2915 in L1, at 2915 in L5 \& at 2919 in L9 which indicated the graphitic nature of these Carbon nano materials. In above three Raman spectra it was studied that with respect to temperature, as the temperature increased, the ratio of defect in turn increased, it may be due to aggregation of molecules. Similarly, in the case of Hydrogen gas produced more defects than Nitrogen and Argon and with respect to duration of pyrolysis, 2 hrs revealed more defect than $3 \mathrm{hrs}$ and $1 \mathrm{hr}$.

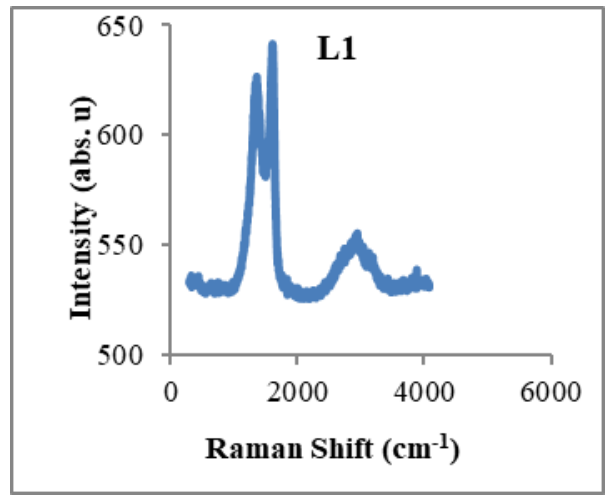

(a) S. cumini seed $\left(\mathrm{Ar}, 800^{\circ} \mathrm{C}, 1 \mathrm{hr}\right)$

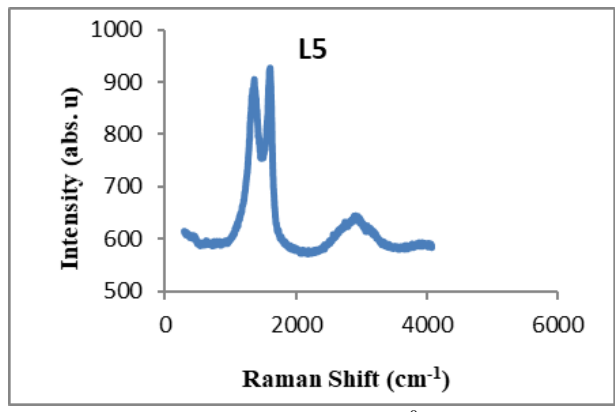

(b) $S$. cumini seed $\left(\mathrm{N}_{2}, 900^{\circ} \mathrm{C}, 3 \mathrm{hrs}\right)$

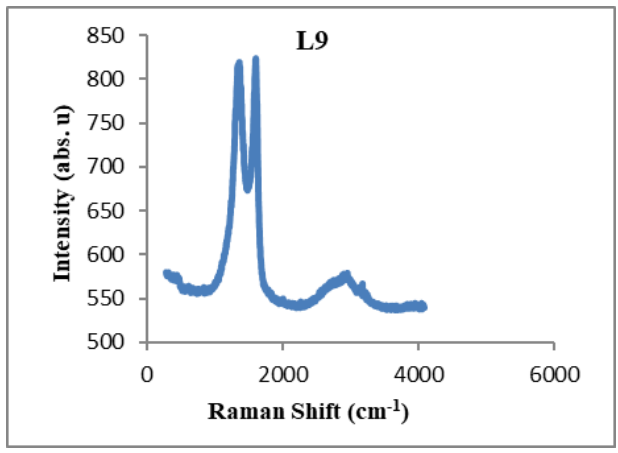

(c) $\mathrm{S}$. cumini seed $\left(\mathrm{H}_{2}, 1000^{\circ} \mathrm{C}, 2 \mathrm{hrs}\right)$

Fig. 5. Raman spectra of L1 (Precursor- Syzygium cumini seed, Temp$800^{\circ} \mathrm{C}$, Gas- Argon, Duration- $1 \mathrm{hr}$ ), (B)- Raman spectra of L5 (PrecursorSyzygium cumini seed, Temp- $900^{\circ} \mathrm{C}$, Gas- Nitrogen, Duration- $3 \mathrm{hrs),} \mathrm{(C)-}$ Raman spectra of L9 (Precursor- Syzygium cumini seed, Temp- $1000^{\circ} \mathrm{C}$, GasHydrogen, Duration- 2 hrs)

\section{F. Raman Spectra of Tamarindus indica Seed}

In the Raman spectra of Taguchi optimized Tamarindus indica (fig. 6) seeds D- band of L2 was at 1365, L6 at 1364 \& L7 at 1367 and G- band of L2 at 1600, L6 at $1601 \&$ L7 at 1600 revealing thereby, the presence of $\mathrm{sp}^{3}$ and $\mathrm{sp}^{2}$ carbon with defect. The ratio of it its intensities show the defect in these materials. ID/IG ratio of L2 is 0.937 , L6 is $0.939 \& \mathrm{~L} 7$ is 0.912 . An additional blunt 2D peak reveals at 2810, in L2, at 2811 in L6 \& at 2819 in L7 showed the graphitic nature of those Carbon nano materials. 


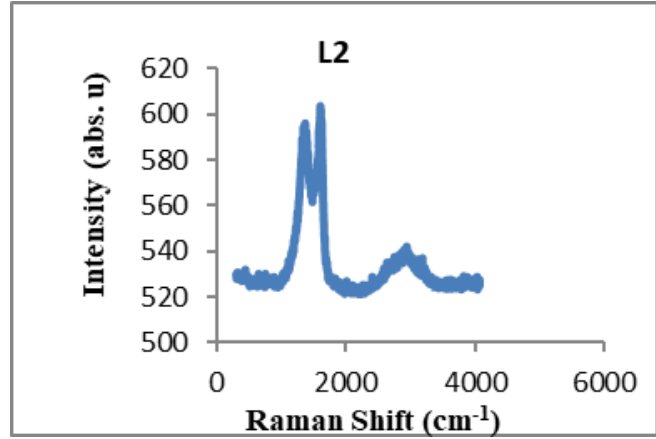

(a) T. indica seed $\left(\mathrm{Ar}, 900^{\circ} \mathrm{C}, 2 \mathrm{hrs}\right)$

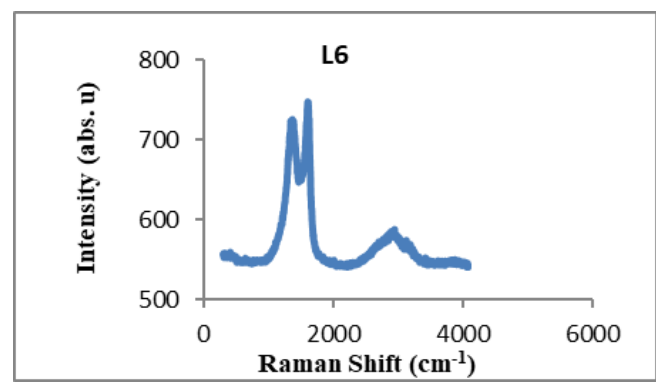

(b) T. indica seed $\left(\mathrm{N}_{2}, 1000^{\circ} \mathrm{C}, 1 \mathrm{hr}\right)$

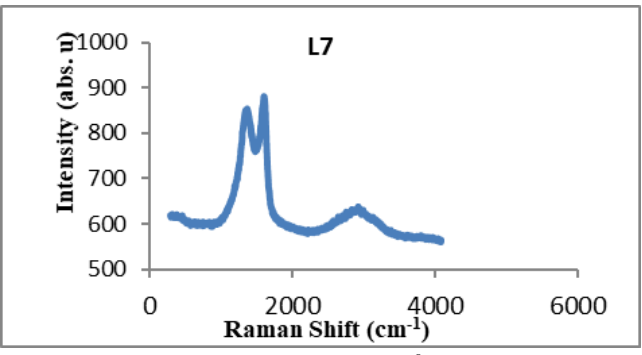

(c) T. indica seed $\left(\mathrm{H}_{2}, 800^{\circ} \mathrm{C}, 3 \mathrm{hrs}\right)$

Fig. 6. a) Raman spectra of L2 (Precursor-Tamarindus indica seed, Temp- $900^{\circ} \mathrm{C}$, Gas- Argon, Duration- 2 hrs), b) Raman spectra of L6 (Precursor- Tamarindus indica seed, Temp- $1000^{\circ} \mathrm{C}$, Gas- Nitrogen, Duration$1 \mathrm{hr}$ ), c) Raman spectra of L7 (Precursor- Tamarindus indica seed, Temp$800^{\circ} \mathrm{C}$, Gas- Hydrogen, Duration- $3 \mathrm{hrs}$ ).

\section{G. Raman Spectra of Litchi chinensis Seed}

In the Raman spectra of Taguchi optimized Litchi chinensis seeds (fig. 7) levels show the sharp peak of D- band L3 at 1354, L4 at $1367 \&$ L8 at 1366 and G- band of L3 at 1619, L4 at 1610 \& L8 at 1602 due to the presence of $\mathrm{sp}^{3}$ and $\mathrm{sp}^{2}$ carbon with defect. The ratio of it its intensities show the defect in these materials. ID/IG ratio of L3 is $0.937, \mathrm{~L} 6$ is $0.939 \& \mathrm{~L} 7$ is 0.912 . An additional blunt 2D peak reveals at 2810, in L2, at 2811 in L6 \& at 2819 in L7 showing the graphitic nature of those carbon nano materials.

In L3, L4 \& L8, the presence of broad peak of 2D peak at $2911,2900 \& 2920$ showed samples being graphitic in nature.

Bhardwaj et al. (2007) [27] studied on carbon materials of different seeds and found that $\mathrm{I}_{\mathrm{G}} / \mathrm{I}_{\mathrm{D}}$ ratio in soap nut seeds and bamboo fibre had highest value suggesting that it contained more graphitic carbon than disorder carbon atoms.

In the present studies, the analysis of CNMs were done on the basis of $\mathrm{D}$ banding, $\mathrm{G}$ banding and 2D peaks obtained with this technique and structural information was interpreted (table 6). It was found that the CNMs from carbohydrate rich seeds (Tamarindus indica, Syzygium cumini and Litchi chinensis) produced:

$$
\begin{aligned}
& \mathrm{D} \text { band }-1354-1367 \mathrm{~cm}-1 \\
& \mathrm{G} \text { band }-1600-1619 \mathrm{~cm}-1 \\
& 2 \mathrm{D} \text { peak }-2900-2920 \mathrm{~cm}-1
\end{aligned}
$$

On account of the above observation it is sumrised that the CNM synthesized from the aforesaid non-edible seed precursors possessed prevailing graphitic constitution along with some graphene like structure.

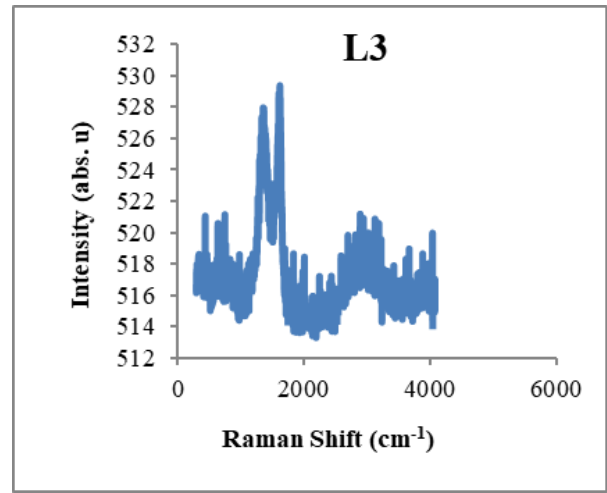

(a) L. chinensis seeds $\left(\mathrm{Ar}, 1000^{\circ} \mathrm{C}, 3 \mathrm{hrs}\right)$

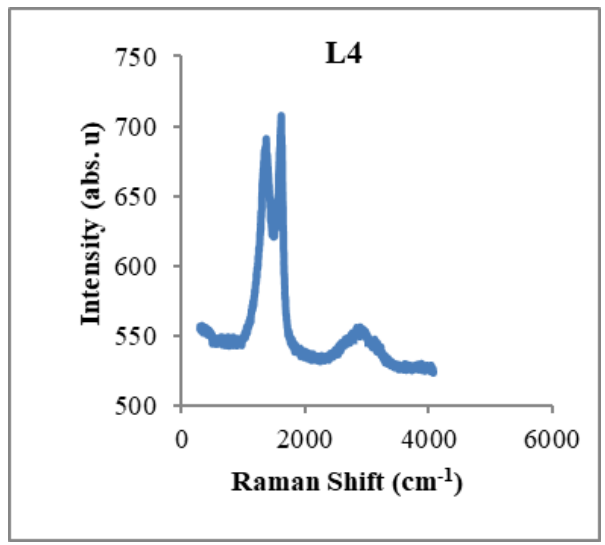

(b) L. chinensis $\operatorname{seed}\left(\mathrm{N}_{2}, 800^{\circ} \mathrm{C}, 2 \mathrm{hrs}\right)$

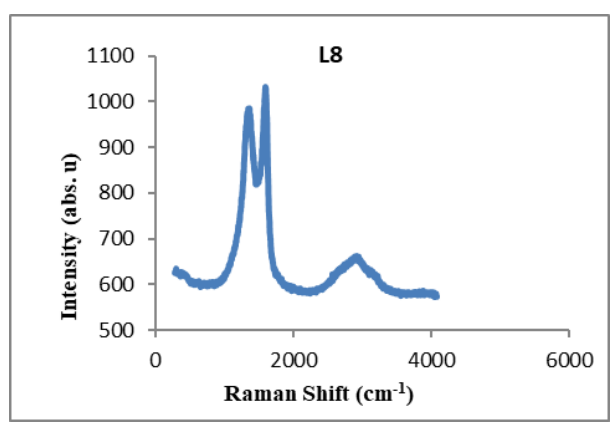

(c) L. chinensis seed $\left(\mathrm{H}_{2,}, 900^{\circ} \mathrm{C}, 1 \mathrm{hr}\right)$

Fig. 7. a) Raman spectra of L3 (Precursor- Litchi chinensis seed, Temp$1000^{\circ} \mathrm{C}$, Gas-Hydrogen, Duration- $3 \mathrm{hrs}$ ), b) Raman spectra of L4 (PrecursorLitchi chinensis seed, Temp- $800^{\circ} \mathrm{C}$, Gas- Nitrogen, Duration- 2 hrs), c) Raman spectra of L8 (Precursor- Litchi chinensis seed, Temp- $900^{\circ} \mathrm{C}$, GasHydrogen, Duration- $1 \mathrm{hr}$ ) 


\section{Conclusion}

Carbon nano materials (CNM) synthesized from biological precursors carbohydrate rich non-edible seeds (S. cumini, $M$. Indica and $A$. indica) have been synthesized by CVD method using single zone CVD furnace without using metal catalyst. The process parameters have been optimized for the bulk growth of CNM from these seeds by Taguchi optimization method in which controlling parameters are carbohydrate rich non-edible seeds ( $S$. cumini, $T$. Indica and L. chinensis) as a precursors, temperature $\left(800^{\circ} \mathrm{C}, 900^{\circ} \mathrm{C}\right.$ and $\left.1000^{\circ} \mathrm{C}\right)$, carrier gas (Ar, $\mathrm{N}_{2}$ and $\mathrm{H}_{2}$ ) and duration of pyrolysis (1 hr, $2 \mathrm{hrs}$ and $3 \mathrm{Hrs}$ ). This experiment showed that T.indica seed as a precursor, $900^{\circ} \mathrm{C}$ temperature, Argon as a carrier gas and $2 \mathrm{hrs}$ duration of pyrolysis are the best parameters for the synthesis of CNM in large scale from these precursors. SEM characterization of synthesized CNM shows plates like morphology with smooth and rough surfaces and the size range of obtained CNM was approx 20-2500 nm. Raman spectroscopy reads the interactions of electromagnetic wave with matter and helps us to information regarding molecule structure. In Raman spectroscopy, the intensity of peak is placed on Y-axis ad frequency on $\mathrm{X}$-axis. Frequency depends on the mass of the atoms and the strength of the bonds holding them. Hence sp2 hybridized carbon in $>\mathrm{C}=\mathrm{C}<$ bond $\left(1600 \mathrm{~cm}^{-}{ }^{1}\right)$ have higher frequency up to $3000 \mathrm{~cm}^{-1}$ while $-\mathrm{C}-\mathrm{C}$ - bonds have as low as $800 \mathrm{~cm}^{-}{ }^{1}$. The two other parameters in the name of D band is caused by the disorder structure of graphene due to the $\mathrm{sp} 2$ hybridized carbon resonance and $\mathrm{G}$ bands is caused by the stretching of $\mathrm{C}-\mathrm{C}$ bonds in graphitic material and is common to all sp2 hybridized carbon. Apart from this, all types of sp2 carbons exhibited a very strong peak in the region/ range -> $2500-2800 \mathrm{~cm}^{-}{ }^{-}$. This is Raman signature of graphitic material and is termed $2 \mathrm{D}$ band.

\section{Acknowledgement}

Authors wish to acknowledge the financial and laboratory support provided by the authorities of nsnRc, SICES college, Ambernath and also specially thanks to University Department of Botany, T. M. Bhagalpur University, Bhagalpur for laboratory.

\section{References}

[1] M. Sharon, N. Sundarakoteeswaran, P. D. Kichambre, M. Kumar, Y. Ando, and X. Zhao, "Semiconducting carbon films from a natural source camphor", Diamond and Related Materials, 8, 485-489,1991.

[2] M. Sharon, M. Kumar, P. D. Kichambre, N. R. Avery, and K. J. Black, "Lithium-Ion intercalation into carbons derived from pyrolysis of camphor", Molecular crystal and Liquid crystal, 340, 523-528, 2000.

[3] M. Sharon, D. Pradhan, M. Kumar, Y. Ando, "NanoOctopus: A new form of branching carbon nanofiber", J. Nanoscience and nanotechnology, 3,3, 1-3, 2003.

[4] M. Sharon \& M. Sharon, "Carbon Nano Forms and Applications", first ed. McGraw Hill, USA, 2010

[5] M. Kumar and Y. Ando, "Chemical Vapor Deposition of Carbon Nanotubes: A Review on Growth Mechanism and Mass Production", Journal of Nanoscience and Nanotechnology, 10, 3739-3758, 2010.
[6] K. Koziol, B. O. Boskovich, N. Yahya, "Synthesis of Carbon Nanostructures by CVD Method, Carbon and Oxide Nanostructures", Advanced Structural Materials, 5, 23-49, 2010.

[7] C. R. Bhattacharjee and A. Nath, "Chemical Vapour Deposition(CVD) Technique and the Synthesis of Carbon Nanomaterials (CNMs)", J. Of Chemical and Pharmaceutical Research,4(1),706-713,2012.

[8] C. Oncel and Y. Yurum, "Carbon nanotube synthesis via the catalytic CVD method: a review on the effect of reaction parameters", Fullerenes, Nanotubes and Carbon nanostructures,14,17-37,2006.

[9] G. Zhenga, H.Sanob, Y. Uchiyamac, "Parameters Affecting the Structure and Yield of Carbon Nanotubes in CVD Method", Material Science Forum, 544-545,773-776,2007.

[10] M.V.Jayaprakasan, K. Viswanathan and P. P. Pradyumnan, "Nanocarbon Material from Edible Oils: Synthesis and Characterization", Journal of Applied Physics, 3, 6, 51-58, 2013.

[11] P.S.Venkatanarayan, R.Velmurugan and A. Joseph Stanley, "Experimental Characterisation of Catalyst Free Carbon Nanomaterials from Mixed Vegetable and Animal Base Oils through Modified Traditional Process", Journal of Nanomaterials, 2011,1-11,2011.

[12] M. V. Jayaprakasan, K. Viswanathan, P. P. Pradyumnan, "Synthesis of Nanocarbon Powder from Sesame Oil and Its SEM Characterization", International Journal of Scientific and Research Publications,3,5,14,2013 .

[13] Karthikeyan, S., \& Mahalingam, P. (2010). Studies of yield and nature of multi-walled carbon nanotubes synthesized by spray pyrolysis of pine oil at different temperatures. Int. J. Nanotechnol. Appl, 4(3), 189-197.

[14] K. Gergova, N. Petrov, and S. Eser (1994) "Adsorption properties and microstructureof activated carbons produced from agricultural byproducts by steam pyrolysis," Carbon. 32, 693-703.

[15] K. Munusamy, R.S. Somani, and H.C. Bajaj (2011); "Carbon for methane uptake," BioResourses 6(1), 537-551.

[16] Sharon, M., Bhardwaj, S., Jaybhaye, S., Sathiyamoorthy, D., Dasgupta, K., \& Sharon, M. (2008). Hydrogen adsorption by carbon nanomaterials from natural source. Asian J Exp Sci, 22(2), 75-88.

[17] Gijare, S., Jebin, S., \& Sharon, M. (2016). Impact of Catalyst on the Synthesis of Carbon Nano Materials from Castor Seeds by Chemical Vapour Deposition Method. Advanced Science Letters, 22(4), 1003-1007.

[18] S. Tripathi, M. Sharon, Maheshwar, N. N. Maldar, J. Shukla, M.Sharon, "Nanocarbon synthesis using plant oil and differential responses to various parameters optimized using the Taguchi method", Carbon Letters, 13,4,210-217,2013.

[19] S. R. Ravella, C. Ganesh, P.R. Shetty and P.J. Hobbs, "The Taguchi Methadology as a Statistical Tool for Biotechnological Applications: A Critical Appraisal," Biotechnology Journal, Vol. 3, No. 4, 2008 pp, 510523.

[20] H. Gitlow, A. Alan Oppenheim and R. Oppenheim, "Tools and Methods for the Improvement of Quality," Von Hoffman Press Inc., Boston, 1989.

[21] S. Maghsoodloo, G. Ozdemir, V. Jorden and C. H. Husang, "Strengths and Limitations of Taguchi's Contributions to Quality, Manufacturing, and Process Engineering," Journal of Manufacturing System, Vol. 23, No. 2, 2004, pp. 73-126.

[22] R. H. Lochner, "Designing for Quality: An Introduction to the Best of Taguchi and Western Methods of Statistical Method Design," Chapman and Hall, London, 1990.

[23] Taguchi, Genichi. "Robust technology development." Mechanical Engineering-CIME, vol. 115, no. 3, Mar. 1993, p. 60+. Gale Academic OneFile,

[24] P. Jagdale et al.; "Carbon Nano Material Synthesis from Polyethylene by Chemical Vapour Deposition" Advances in Materials Physics and Chemistry, 2012, 2, 1-10.

[25] M Sharon, M. Sharon, G. Kalita \& B. Mukherjee (2011). Hydrogen storage by carbon fibers synthesized by pyrolysis of cotton fibers. Carbon Lett, 12, 39-43.

[26] V. Chaudhary, \& A. K. Bhowmick (2015). "Green synthesis of fluorescent carbon nanoparticles from lychee (Litchi chinensis) plant." Korean Journal of Chemical Engineering, 32(8), 1707-1711.

[27] Bhardwaj, S., Sharon, M., Ishihara, T., Jayabhaye, S., Afre, R., Soga, T., \& Sharon, M. (2007). Carbon material from natural sources as an anode in lithium secondary battery. Carbon letters, 8(4), 285-291. 